\title{
Discovery of a Novel Series of Thienopyrimidine as Highly Potent and Selective PI3K Inhibitors
}

\author{
Fangbin Han, ${ }^{\dagger}$ Songwen Lin, ${ }^{\dagger}$ Peng Liu, Xiujie Liu, Jing Tao, Xiaobing Deng, Chongqin Yi, and Heng Xu* \\ PKUCare Pharmaceutical R\&D Center, A106-109, Biotech Innovation Works, No. 29 Life Science Park Road, Changping District, \\ Beijing 102206, P. R. China
}

\section{Supporting Information}

ABSTRACT: Inhibition of the phosphoinositide 3-kinase (PI3K)/AKT/mammalian target of rapamycin (mTOR) signaling pathway provides a promising new approach for cancer therapy. Through a rational design, a novel series of thienopyrimidine was discovered as highly potent and selective PI3K inhibitors. These thienopyrimidine derivatives were demonstrated to bear nanomolar PI3K $\alpha$ inhibitory potency with over 100 -fold selectivity against mTOR kinase. The lead compounds $6 \mathrm{~g}$ and $6 \mathrm{k}$ showed good developability profiles in cell-based proliferation and ADME assays. In this communication, their design, synthesis, structure-activity relationship, selectivity, and some developability properties are described.

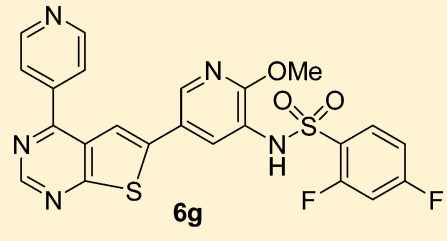

$\mathrm{IC}_{50}(\mathrm{PI} 3 \mathrm{K \alpha})=2.07 \mathrm{nM}$

$\mathrm{IC}_{50}(\mathrm{mTOR})=218 \mathrm{nM}$

Selectivity $(\mathrm{mTOR} / \mathrm{PI} 3 \mathrm{Ka})=105$-fold

T47D $I_{50}=0.66 \mu \mathrm{M}$

$\mathrm{H} 460 \mathrm{IC}_{50}=0.42 \mu \mathrm{M}$

KEYWORDS: thienopyrimidines, phosphoinositide 3-kinase, mammalian target of rapamycin, dual inhibitors, selective PI3K inhibitors

$\mathrm{T}$ he phosphoinositide 3-kinase (PI3K)/AKT/the mammalian target of rapamycin (mTOR) signal transduction pathway is involved in many essential cellular functions including cell growth, proliferation, differentiation, motility, survival, and intracellular trafficking. ${ }^{1,2}$ The PI3Ks constitute a lipid kinase family and are divided into three different classes (class I, II, and III) according to their sequence, homology, and substrate preferences. ${ }^{2}$ Of them, class I PI3Ks are the most widely understood and are subdivided into class IA (PI3K $\alpha, \beta$, and $\delta$ ) isoforms and class IB (PI3K $\gamma$ ) isoforms. ${ }^{2}$ Activated by receptor tyrosine kinases and Tas and Rho family GTPases, the PI3Ks phosphorylate at the 3-hydroxyl position of PIP2 (phosphatidylinositol 4,5-diphosphate) to generate PIP3 (phosphatidylinositol 3,4,5-triphosphate), a potent secondary messenger that results in the activation of several downstream effectors, including the serine-threonine kinase, AKT (also known as protein kinase B or PKB). ${ }^{2}$ Subsequently, activated AKT triggers a signal transduction cascade that ultimately stimulates mTOR mTOR containing two distinct complexes (mTORC1 and mTORC2) plays an integral key role in regulating PI3K/AKT activation and signaling through positive and negative feedback loops. ${ }^{2,3}$

Abundant evidence from genomic analysis has revealed that many components of the $\mathrm{PI} / \mathrm{K} / \mathrm{AKT} / \mathrm{mTOR}$ pathway were frequently mutated or altered in numerous forms of human cancers. ${ }^{2,4}$ For example, the PI3K catalytic subunit $\alpha$-isoform gene encoding the p110 $\alpha$ (PIK3CA) is one of the most highly mutated oncogenes, and its high mutational frequencies have been demonstrated in breast, colorectal, liver, and other cancers. In addition, mTOR was the first node of this pathway to be targeted in the clinic, and the association between mTOR and cancers has been validated by several approved drugs such as Afinitor and Torisel. Hence, targeting this pathway for cancer therapeutics has been intensively pursued by many industrial and academic research groups. Noteworthy, the kinase domain of mTOR and the p110 catalytic subunit of the class I PI3Ks share a high degree of similarity/sequence homology, 5,6 prompting to generate $\mathrm{PI} 3 \mathrm{~K} / \mathrm{mTOR}$ dual inhibitors, which target two nodal points in the pathway concurrently to offer an augment on better efficacy and less likelihood to induce drug resistance, etc. ${ }^{2,7}$ Parallel with PI3K/mTOR dual inhibitors, the selective PI3K inhibitors to avoid extra toxicity carried by mTOR kinase inhibitory activity for achieving a balanced efficacy and safety profile have also received great attention. ${ }^{8}$ Both PI3K/mTOR dual inhibitors (e.g., GSK2126458 and PKI587, Figure 1) and selective PI3K inhibitors (e.g., GDC-0941 and BKM120, Figure 1) have been advanced into clinical evaluation. $^{9-12}$

Among PI3K/mTOR dual inhibitors reported to date, GSK2126458, as shown in Figure 1, is one of most potent structures with a $K_{\mathrm{i}}$ of $0.019,0.18$, and $0.30 \mathrm{nM}$ for $\mathrm{PI} 3 \mathrm{~K} \alpha$, mTORC1, and mTORC2, respectively. ${ }^{9}$ Its high in vitro potencies were well translated into in vivo efficacies across a broad spectrum of antitumor models, paving the way for its clinical development. ${ }^{13}$ Its chemical structure features quinoline, sulfonamide, and methoxylpyridine moieties, which forms key hydrogen bonds with Val882, Lys833, and an active water molecule, respectively, as determined from a cocrystal structure with PI3K $\gamma .{ }^{9}$ Apparently, quinoline core is a cornerstone of the structure, for not only forming its own critical hydrogen bonding with the target enzyme but projecting other moieties

Received: December 5, 2014

Accepted: March 11, 2015

Published: March 11, 2015 

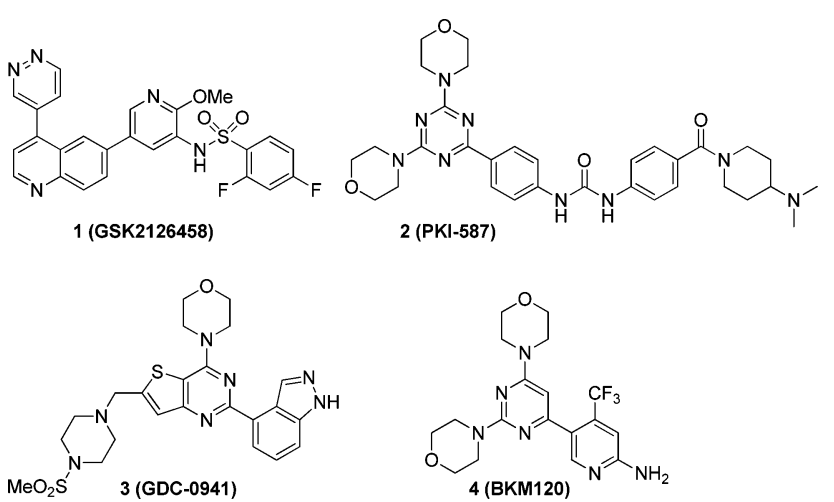

Figure 1. PI3K/mTOR dual inhibitors (1 and 2) and the class I selective PI3K inhibitors (3 and 4).

appropriately to access additional interactions. Although quite a few PI3K/mTOR inhibitors were derived from this chemical series, the structure-activity relationship (SAR) focused on the quinoline region has barely been reported. Possibilities of further optimizing the potency as well as other drug-like properties by replacement of quinoline still remain unclear. Herein, we describe our research progress that led to generate a structurally novel thienopyrimidine series as potent PI3K inhibitors with good selectivity against mTOR.

During the course of our SAR investigation, compound 5a with a quinoline core was first synthesized and evaluated as a close analogue to GSK2126458 for a reference standard (Table 1). Next, the aromatic $\mathrm{CH}$ at 8-position of quinoline was replaced by a nitrogen and the resulting naphthyridine $\mathbf{5 b}$ displayed a significant drop of potency in both $\mathrm{PI} 3 \mathrm{~K} \alpha$ and

Table 1. PI3K $\alpha$ and mTOR Potency Data for Compounds $5 a-h^{14}$

Sompd

mTOR assays relative to 5a ( 350 -fold decrease for PI3K $\alpha$ and $\sim 90$-fold decrease for mTOR). Apparently, this position is not well tolerated with nitrogen, and the corresponding loss of potency could be explained by unfavorable interaction between nitrogen and the carbonyl of Glu880 in the target protein as observed from a Amgen chemical series. ${ }^{15}$ When nitrogen was moved from 8- to 7-position, 1,7-naphthyridine 5c gained back some degree of potency but was still around 10- and 4-fold less potent against PI3K $\alpha$ and mTOR enzymes than 5a, respectively. With SAR expansion, quinazoline $\mathbf{5 d}$, pyridopyrimidine 5e, and cinnoline $5 \mathbf{f}$ were also investigated. Noteworthy, N-3 nitrogen (5d and $5 \mathbf{e}$ ) retains the $\mathrm{PI} 3 \mathrm{~K} \alpha$ and mTOR potency (5d vs $\mathbf{5} \mathbf{a}$ and $\mathbf{5 e}$ vs $\mathbf{5 b}$ ), while $\mathrm{N}-2$ nitrogen (cinnoline 5f) exhibited a slight decrease of potency for PI3K $\alpha$ (5f vs 5a: <3-fold) and a pronounced decrease for mTOR (5f vs 5a: $>25$-fold). Through scanning the above 2-, 3-, 7-, and 8position of quinoline, it was clearly found that only 3-position was tolerated for nitrogen replacement without loss of any PI3K $\alpha$ and mTOR inhibitory activities. When 2-amino group was incorporated, pyridopyrimidine $\mathbf{5 g}$ showed slightly enhanced $\mathrm{PI} 3 \mathrm{~K} \alpha$ inhibitory activities (5g vs $\mathbf{5 e}$ ), and a similar trend was also observed for quinazoline $5 \mathrm{~h}$ ( $5 \mathrm{~h}$ vs $\mathbf{5 d}$ ). Of particular note, selectivity of PI $3 \mathrm{~K} \alpha$ against mTOR was all less than 10-fold for all compounds listed in Table 1 except for compound $\mathbf{5 f}$ ( $\sim 80-$ fold). Synthesis of compounds $\mathbf{5 a}-\mathbf{h}$ was performed according to the revised literature procedures. ${ }^{16-21}$

In addition to the approach of inserting nitrogen into quinoline ring as illustrated above, the bicyclic thienopyrimidine core was further explored for a new structural scaffold (Table 2). The simple methoxylpyridine 6a only displayed single-digit micromolar enzymatic $\mathrm{PI} 3 \mathrm{~K} \alpha$ potency with an $\mathrm{IC}_{50}$ of $1.22 \mu \mathrm{M}$. The potency of pyrimidine $\mathbf{6} \mathbf{b}$ fell into the same order of magnitude with that of the pyridine $(1.22 \mu \mathrm{M}$ vs 3.49 $\mu \mathrm{M})$. The small electron-withdrawing fluoride group (e.g., 6c) on the pyridine did not offer the potency benefit. Similar to several other published chemical series, incorporation of sulfonamide functionality to the 3-position of the methoxylpyridine on this thienopyrimidine scaffold significantly boosted the potency (e.g., 6d-6i). This great improvement could be explained by the strong interaction picked up by the sulfonamide with Lys 833 within the affinity pocket, more specifically, the charge interaction derived from the deprotonated sulfonamide nitrogen at physiological conditions. ${ }^{9,22}$ In particular, compound $6 \mathrm{~g}$ exhibited an $\mathrm{IC}_{50}$ of $2.07 \mathrm{nM}$ in PI3K $\alpha$ assay (Table 2), which is around 20-fold less potent compared to $\mathbf{5 d}$. It is likely that the sulfur in the thienopyrimidine core causes a less favorable interaction with the carbonyl of Glu880 in a similar situation as described earlier for the nitrogen at the 8-position of the pyridopyrimidine core in 5 e. ${ }^{15}$ The binding mode between $6 \mathrm{~g}$ and $\mathrm{PI} 3 \mathrm{~K} \gamma$ as a surrogate protein was proposed in Figure 2, illustrating the possible lone pair repulsion between the sulfur in the thienopyrimidine core and carbonyl oxygen of Glu880. However, relative to the pyridopyrimidine $5 \mathbf{e}$, the bicyclic thienopyrimidine confers the PI3K $\alpha$ potency enhancement (6g vs 5e: 2.07 vs $51.7 \mathrm{nM}$ ). Modification on the thienopyrimidine ring by attaching a methyl group (6e) resulted in a significant potency drop. With no apparent advantages gained from this variation, further SAR investigation retained the parent thienopyrimidine core to focus on the methoxylpyridine ring. When methoxyl group was replaced by other simple substituents $(\mathrm{Me}$ or $\mathrm{Cl})$, it was found that, in comparison to $\mathbf{6 g}$, methylpyridine $6 \mathbf{j}$ exhibited similar PI3K $\alpha$ potency ( $1.70 \mathrm{nM}$ vs $2.07 \mathrm{nM}$ ), while chloride pyridine 
Table 2. PI3K and mTOR Potency Data for Compounds $6 a-m^{14}$

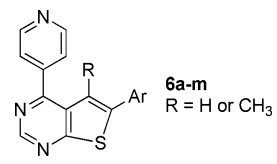

\begin{tabular}{|c|c|c|c|c|c|}
\hline Compd & $\mathrm{R}$ & $\mathrm{Ar}$ & $\begin{array}{c}\mathrm{PI} 3 \mathrm{~K} a \\
\mathrm{IC}_{50} \\
(\mathrm{nM})\end{array}$ & $\begin{array}{c}\text { mTOR } \\
\mathrm{IC}_{50} \\
(\mathrm{nM})\end{array}$ & $\begin{array}{c}\text { Selectivity } \\
\text { (mTOR/ } \\
\text { PI3Ka) }\end{array}$ \\
\hline $6 a$ & $\mathrm{H}$ & & 1228 & $\mathrm{ND}^{a}$ & I \\
\hline $6 b$ & $\mathrm{H}$ & & 3494 & $\mathrm{ND}^{a}$ & / \\
\hline $6 c$ & $\mathrm{H}$ & & $>2500$ & $\mathrm{ND}^{a}$ & / \\
\hline 6d & $\mathrm{H}$ & & 43.1 & $\mathrm{ND}^{a}$ & / \\
\hline $6 e$ & $\mathrm{Me}$ & & 72.3 & $\mathrm{ND}^{a}$ & I \\
\hline $6 f$ & $\mathrm{H}$ & & 17.0 & $\mathrm{ND}^{a}$ & / \\
\hline $6 g$ & $\mathrm{H}$ & & 2.07 & 218 & 105 \\
\hline $6 h$ & $\mathrm{H}$ & & 3.60 & 363 & 100 \\
\hline $6 i$ & $\mathrm{H}$ & & 1.30 & 67.9 & 52 \\
\hline $6 \mathbf{j}$ & $\mathrm{H}$ & & 1.70 & 345 & 203 \\
\hline $6 k$ & $\mathrm{H}$ & & 0.23 & 53.6 & 233 \\
\hline 61 & $\mathrm{H}$ & & 0.30 & 43.7 & 146 \\
\hline $6 \mathrm{~m}$ & $\mathrm{H}$ & & 0.15 & 25.8 & 172 \\
\hline
\end{tabular}

${ }^{a} \mathrm{ND}=$ not determined.

6k generated around 10 -fold $\mathrm{PI} 3 \mathrm{~K} \alpha$ potency enhancement $(0.23 \mathrm{nM}$ vs $2.07 \mathrm{nM})$. This significant potency enhancement was also demonstrated by two more chlorine substituted pyridines $6 \mathbf{l}$ and $6 \mathrm{~m}$. Notably, with subnanomolar $\mathrm{IC}_{50} \mathrm{~s}$ achieved, $\mathrm{PI} 3 \mathrm{~K} \alpha$ potency level from thienopyrimidine series has been optimized up to the similarly high level from quinoline series.

The general synthetic approach for above thienopyrimidines was described in Scheme 1: cyclization of compound 7 with formamidine acetate afforded the bicyclic thienopyrimidine core $\mathbf{8}$, which was then brominated with liquid bromine to give compound 9. Compound 9 was then treated with phosphorus oxychloride and sodium iodide subsequently to afford the key intermediate 6-bromo-4-iodiothienopyrimidine 11, which was further coupled with pyridine-4-boronic acid and then various aryl borate or boronic acid to give compounds $6 \mathbf{a}-\mathbf{m}$.

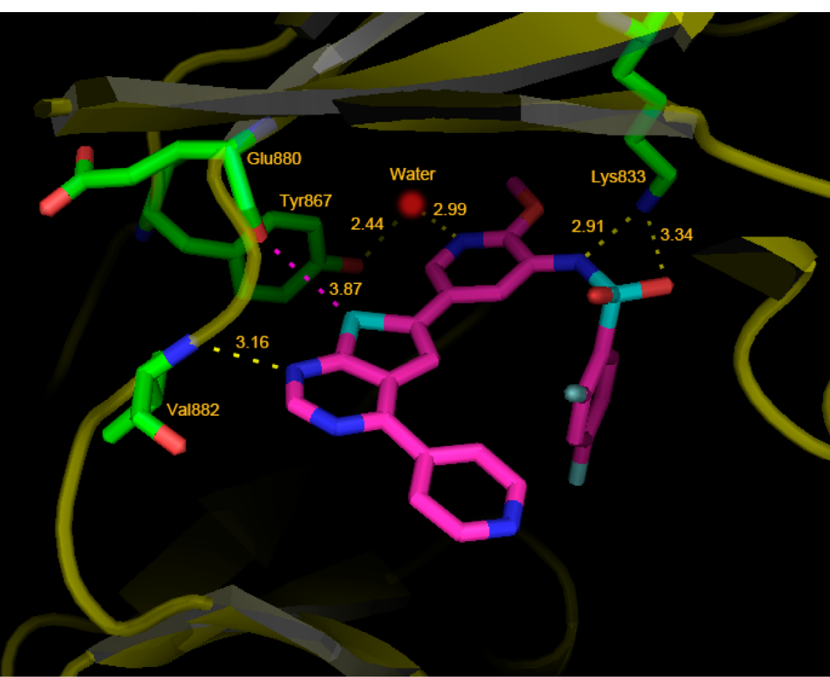

Figure 2. Predicted binding mode for $\mathbf{6 g}$ (shown in stick representation with carbon atoms colored magenta) with $\mathrm{PI} 3 \mathrm{~K} \gamma$ (PDB ID: 3L08). Hydrogen bonding interactions are shown in yellow dashed lines to the hinge region (Val882), Lys833, and the conserved water molecule in the selectivity pocket. The interaction between the sulfur in the thienopyrimidine core of $\mathbf{6 g}$ and carbonyl of Glu880 is demonstrated in magenta dashed line. Images generated using PyMol.

Scheme 1. Synthesis of Compounds $6 a-m^{a}$

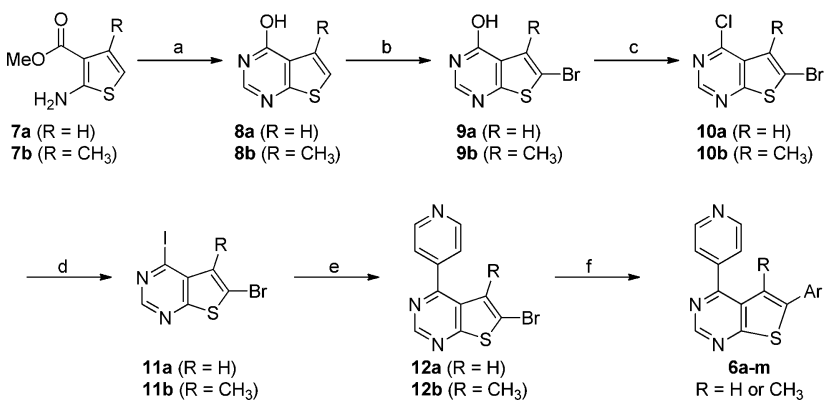

${ }^{a}$ Reagents and conditions: (a) formamidine acetate, NMP, $135^{\circ} \mathrm{C}$, $\mathrm{Ar}$; (b) $\mathrm{Br}_{2}, \mathrm{HOAc}$, rt; (c) $\mathrm{POCl}_{3}$, reflux; (d) NaI, anhydrous dioxane, 105 ${ }^{\circ} \mathrm{C}$, Ar; (e) pyridine-4-boronic acid, $2 \mathrm{~N} \mathrm{~K}_{2} \mathrm{CO}_{3}, \mathrm{Pd}\left(\mathrm{PPh}_{3}\right)_{2} \mathrm{Cl}_{2}$, dioxane, $100{ }^{\circ} \mathrm{C}$; (f) aryl borate or aryl boronic acid, $\mathrm{PdCl}_{2}(\mathrm{dppf}), 2 \mathrm{~N}$ $\mathrm{K}_{2} \mathrm{CO}_{3}$, dioxane, $100{ }^{\circ} \mathrm{C}$.

Of particular interest, these thienopyrimidines showed good $\mathrm{PI} 3 \mathrm{~K} \alpha / \mathrm{mTOR}$ selectivity, and the selectivity was, in general, determined to be around 100-fold. This is a much improved selectivity profile relative to six-membered fused bicyclic rings such as quinoline, naphthyridine, and quinazoline illustrated in Table 1. For the selectivity, we hypothesize that the sulfur in thienopyrimidine was closer to Tyr2225 in mTOR than the corresponding $\mathrm{Tyr}$ residue in $\mathrm{PI} 3 \mathrm{~K} \alpha$, rendering a stronger repulsion for mTOR kinase.

Through the above SAR investigation, novel thienopyrimidine derivatives were identified to bear decent $\mathrm{PI} 3 \mathrm{~K} \alpha$ potency with good mTOR selectivity. Two representative compounds $\mathbf{6 g}$ and $6 \mathrm{k}$ were selected for further profiling. Among the class I PI3K isoforms, $6 \mathbf{g}$ and $6 \mathbf{k}$ were most potent against PI3K $\alpha$ and had single to low double digit nanomolar potencies against $\mathrm{PI} 3 \mathrm{~K} \beta, \mathrm{PI} 3 \mathrm{~K} \delta$, and $\mathrm{PI} 3 \mathrm{~K} \gamma$ (Table 3). Both PAMPA and Caco-2 assays were utilized to test their property of permeability. These two in vitro $\mathrm{ADME}$ assay results were well correlated and showed moderate permeability for $\mathbf{6 g}$ and $\mathbf{6 k}$ (Table 4). For 
Table 3. Class I PI3K Assay Data for $6 \mathrm{~g}$ and $6 \mathrm{k}$

\begin{tabular}{ccccc} 
& \multicolumn{4}{c}{$\mathrm{IC}_{50}(\mathrm{nM})$} \\
\cline { 2 - 5 } Compd & PI3K $\alpha$ & $\mathrm{PI} 3 \mathrm{~K} \beta$ & $\mathrm{PI} 3 \mathrm{~K} \delta$ & $\mathrm{PI} 3 \mathrm{~K} \gamma$ \\
$\mathbf{6 g}$ & 2.07 & 22.5 & 13.3 & 21.1 \\
$\mathbf{6 k}$ & 0.23 & 3.6 & 3.1 & 10.2 \\
\hline
\end{tabular}

Table 4. Permeability Assay Data for $6 \mathrm{~g}$ and $6 \mathrm{k}$

\begin{tabular}{ccccc} 
& & \multicolumn{3}{c}{ Caco-2 $\left(10^{-6} \mathrm{~cm} / \mathrm{s}\right)$} \\
\cline { 3 - 5 } Compd & $\begin{array}{c}\text { PAMPA }\left(10^{-6}\right. \\
\mathrm{cm} / \mathrm{s})\end{array}$ & Papp (A to B) & Papp (B to A) & $\begin{array}{c}\text { Efflux } \\
\text { ratio }\end{array}$ \\
\hline $\mathbf{6 g}$ & 8.0 & 5.6 & 4.5 & 0.8 \\
$\mathbf{6 k}$ & 7.0 & 4.8 & 6.9 & 1.4
\end{tabular}

cellular activities, AKT (Ser 473) phosphorylation assay was conducted with T47D cells in which $\mathbf{6 g}$ exhibited significant inhibitory activity on the downstream AKT phosphorylation with an $\mathrm{IC}_{50}$ of $84.6 \mathrm{nM}$ (Table 5). Compounds $\mathbf{6 g}$ and $6 \mathbf{k}$

Table 5. Cellular Assay Data for $6 \mathrm{~g}$ and $6 \mathrm{k}$

$\begin{array}{clcc}\text { Assay } & \text { Cell line } & \mathbf{6 g} & \mathbf{6 k} \\ \text { pAKT-S473 } \mathrm{IC}_{50}(\mathrm{nM}) & \mathrm{T} 47 \mathrm{D} & 84.6 & \mathrm{ND}^{a} \\ \text { cell growth } \mathrm{IC}_{50}(\mu \mathrm{M}) & \mathrm{U}^{a} 7 \mathrm{MG}^{b} & 4.40 & 4.43 \\ & \mathrm{~T}^{b} \mathrm{D}^{c} & 0.66 & 1.52 \\ & \mathrm{SKOV3}^{c} & 3.74 & 5.20 \\ & \mathrm{H}^{c} 975^{c} & 1.07 & 2.20 \\ & \mathrm{H} 460^{c} & 0.42 & 2.94 \\ & \mathrm{~A} 549^{d} & 3.18 & 8.44\end{array}$

${ }^{a} \mathrm{ND}=$ not determined. ${ }^{b}$ Tumor cell line with PTEN deletion. ${ }^{c}$ Tumor cell line harboring PIK3CA mutation. ${ }^{d}$ Tumor cell line harboring neither PIK3CA mutation nor PTEN deletion.

were also tested in different cancer cell lines for its sensitivity in cell proliferation assays. All cancer cell lines chosen for the experiment either harbor PIK3CA mutations or bear the PTEN deletion except for A549. Compounds $6 \mathrm{~g}$ and $\mathbf{6 k}$ were moderately potent with at least single digit micromolar $\mathrm{IC}_{50} \mathrm{~s}$ across these selected cell lines (Table 5). It was worthy to note that compound $6 \mathrm{~g}$ was more sensitive to nonsmall cell lung cancer cell line $\mathrm{H} 460$ and breast cancer line T47D with $\mathrm{IC}_{50} \mathrm{~s}$ of 0.42 and $0.66 \mu \mathrm{M}$ respectively, while it performed the least inhibitory effect on human brain glioma cell line U87MG ( IC $_{50}$ $=4.4 \mu \mathrm{M})$. The overall profiles of $6 \mathrm{~g}$ and $6 \mathrm{k}$ obtained from in vitro assays support their next phase of in vivo evaluation.

In summary, a novel series of thienopyrimidine was discovered by rational design as highly potent PI3K inhibitors. The most potent compounds identified from this series demonstrated subnanomolar $\mathrm{PI} 3 \mathrm{~K} \alpha$ potency, comparable to those from the known quinoline scaffold. Differing from the quinoline scaffold, thienopyrimidine derivatives confer good PI3K $\alpha /$ mTOR selectivity ( $>100$-fold). The lead compounds $6 \mathrm{~g}$ and $\mathbf{6 k}$ showed acceptable developability profiles in cell-based proliferation and ADME assays. Further optimization of this series as well as in vivo phase of testing including $\mathrm{PK}$ properties and in vivo efficacies will be reported in due course.

\section{ASSOCIATED CONTENT}

\section{S Supporting Information}

Biological assays and experimental procedures. This material is available free of charge via the Internet at http://pubs.acs.org.

\section{AUTHOR INFORMATION}

\section{Corresponding Author}

*Tel: 86-10-80712886. E-mail: xuheng@pkucare-pharm.com.

\section{Author Contributions}

${ }^{\dagger}$ These authors contributed equally to this work.

\section{Notes}

The authors declare no competing financial interest.

\section{ACKNOWLEDGMENTS}

This research was supported in part by Returnee Scientific Innovation Initiative Program of Beijing, China Postdoctoral Science Foundation (2012M510380), and Beijing Postdoctoral Research Foundation (2012ZZ-96).

\section{ABBREVIATIONS}

PI3K, phosphoinositide 3-kinase; mTOR, mammalian target of rapamycin; PTEN, phosphotase and tensin homologue; PAMPA, parallel artificial membrane permeability assay

\section{REFERENCES}

(1) Engelman, J. A.; Luo, J.; Cantley, L. C. The evolution of phosphatidylinositol 3-kinases as regulators of growth and metabolism. Nat. Rev. Genet. 2006, 7, 606-619.

(2) Liu, P. X.; Cheng, H. L.; Roberts, T. M.; Zhao, J. J. Targeting the phosphoinositide 3-kinase pathway in cancer. Nat. Rev. Drug Discovery 2009, 8, 627-644.

(3) Sarbassov, D. D.; Ali, S. M.; Sabatini, D. M. Growing roles for the mTOR pathway. Curr. Opin. Cell Biol. 2005, 17, 596-603.

(4) Vivanco, I.; Sawyers, C. L. The phosphatidylinositol 3-Kinase AKT pathway in human cancer. Nat. Rev. Cancer 2002, 2, 489-501.

(5) Strimpakos, A. S.; Karapanagiotou, E. M.; Wasif Saif, M.; Syrigos, $\mathrm{K}$. N. The role of mTOR in the management of solid tumors: an overview. Cancer Treat. Rev. 2009, 35, 148-159.

(6) Harris, T. E.; Lawrence, J. C., Jr. TOR signaling. Science's STKE 2003, 2003, re15.

(7) Courtney, K. D.; Corcoran, R. B.; Engelman, J. A. The PI3K pathway as drug target in human cancer. J. Clin. Oncol. 2010, 28, $1075-1083$

(8) Liu, K. K.; Zhu, J.; Smith, G. L.; Yin, M. J.; Bailey, S.; Chen, J. H.; Hu, Q.; Huang, Q.; Li, C.; Li, Q. J.; Marx, M. A.; Paderes, G.; Richardson, P. F.; Sach, N. W.; Walls, M.; Wells, P. A.; Baxi, S.; Zou, A. Highly selective and potent thiophenes as PI3K inhibitors with oral antitumor activity. ACS Med. Chem. Lett. 2011, 2, 809-813.

(9) Knight, S. D.; Adams, N. D.; Burgess, J. L.; Chaudhari, A. M.; Darcy, M. G.; Donatelli, C. A.; Luengo, J. I.; Newlander, K. A.; Parrish, C. A.; Ridgers, L.; Sarpong, M. A.; Schmidt, S. J.; Van Aller, G. S.; Carson, J. D.; Diamond, M. A.; Elkins, P. A.; Gardiner, C. M.; Garver, E.; Gilbert, S. A.; Gontarek, R. R.; Jackson, J. R.; Kershner, K. L.; Luo, L.; Raha, K.; Sherk, C. S.; Sung, C.; Sutton, D.; Tummino, P. J.; Wegrzyn, R. J.; Auger, K. R.; Dhanak, D. Discovery of GSK2126458, a highly potent inhibitor of PI $3 \mathrm{~K}$ and the mammalian target of rapamycin. ACS Med. Chem. Lett. 2010, 1, 39-43.

(10) Venkatesan, A. M.; Dehnhardt, C. M.; Delos Santos, E.; Chen, Z.; Dos Santos, O.; Ayral-Kaloustian, S.; Khafizova, G.; Brooijmans, N.; Mallon, R.; Hollander, I.; Feldberg, L.; Lucas, J.; Yu, K.; Gibbons, J.; Abraham, R. T.; Chaudhary, I.; Mansour, T. S. Bis(morpholino1,3,5-triazine) derivatives: potent adenosine $5^{\prime}$-triphosphate competitive phosphatidylinositol-3-kinase/mammalian target of rapamycin inhibitors: discovery of compound 26 (PKI-587), a highly efficacious dual inhibitor. J. Med. Chem. 2010, 53, 2636-2645.

(11) Folkes, A. J.; Ahmadi, K.; Alderton, W. K.; Alix, S.; Baker, S. J.; Box, G.; Chuckowree, I. S.; Clarke, P. A.; Depledge, P.; Eccles, S. A.; Friedman, L. S.; Hayes, A.; Hancox, T. C.; Kugendradas, A.; Lensun, L.; Moore, P.; Olivero, A. G.; Pang, J.; Patel, S.; Pergl-Wilson, G. H.; Raynaud, F. I.; Robson, A.; Saghir, N.; Salphati, L.; Sohal, S.; Ultsch, M. H.; Valenti, M.; Wallweber, H. J.; Wan, N. C.; Wiesmann, C.; 
Workman, P.; Zhyvoloup, A.; Zvelebil, M. J.; Shuttleworth, S. J. The identification of 2-(1H-indazol-4-yl)-6-(4-methanesulfonyl-piperazin1-ylmethyl)-4-morpholin-4-yl-thieno[3,2-d]pyrimidine (GDC-0941) as a potent, selective, orally bioavailable inhibitor of class I PI3 kinase for the treatment of cancer. J. Med. Chem. 2008, 51, 5522-5532.

(12) Burger, M. T.; Pecchi, S.; Wagman, A.; Ni, Z. J.; Knapp, M.; Hendrickson, T.; Atallah, G.; Pfister, K.; Zhang, Y.; Bartulis, S.; Frazier, K.; Ng, S.; Smith, A.; Verhagen, J.; Haznedar, J.; Huh, K.; Iwanowicz, E.; Xin, X.; Menezes, D.; Merritt, H.; Lee, I.; Wiesmann, M.; Kaufman, S.; Crawford, K.; Chin, M.; Bussiere, D.; Shoemaker, K.; Zaror, I.; Maira, S. M.; Voliva, C. F. Identification of NVP-BKM120 as a potent, selective, orally bioavailable Class I PI3 kinase inhibitor for treating cancer. ACS Med. Chem. Lett. 2011, 2, 774-779.

(13) Dose-Escalation Study of GSK2126458 (FTIH). http:// clinicaltrials.gov/ct2/show $/$ NCT00972686?term $=$ gsk2 126458\&rank= 3.

(14) BEZ-235 was a positive control in our assays, and its $\mathrm{IC}_{50}$ s were determined to be 6.2 and $11.5 \mathrm{nM}$ for PI3K $\alpha$ and mTOR respectively. See Supporting Information for the assay protocols.

(15) Nishimura, N.; Siegmund, A.; Liu, L.; Yang, K.; Bryan, M. C.; Andrews, K. L.; Bo, Y.; Booker, S. K.; Caenepeel, S.; Freeman, D.; Liao, H.; McCarter, J.; Mullady, E. L.; San Miguel, T.; Subramanian, R.; Tamayo, N.; Wang, L.; Whittington, D. A.; Zalameda, L.; Zhang, N.; Hughes, P. E.; Norman, M. H. Phospshoinositide 3-kinase $(\mathrm{PI} 3 \mathrm{~K}) /$ mammalian target of rapamycin (mTOR) dual inhibitors: discovery and structure-activity relationships of a series of quinoline and quinoxaline derivatives. J. Med. Chem. 2011, 54, 4735-4751.

(16) Adams, N. D.; Burgess, J. L.; Darcy, M. G.; Donatelli, C. A.; Knight, S. D.; Newlander, K. A.; Ridgers, L.; Sarpong, M.; Schmidt, S. J. Quinoline derivatives as PI3 kinase inhibitors. WO2008144463, November 27, 2008.

(17) Wissner, A.; Berger, D. M.; Boschelli, D. H.; Floyd, M. B., Jr; Greenberger, L. M.; Gruber, B. C.; Johnson, B. D.; Mamuya, N.; Nilakantan, R.; Reich, M. F.; Shen, R.; Tsou, H. R; Upeslacis, E.; Wang, Y. F.; Wu, B.; Ye, F.; Zhang, N. 4-Anilino-6,7-dialkoxyquinoline-3-carbonitrile inhibitors of epidermal growth factor receptor kinase and their bioisosteric relationship to the 4-anilino-6,7dialkoxyquinazoline inhibitors. J. Med. Chem. 2000, 43, 3244-3256.

(18) Lin, S. W.; Han, F. B.; Liu, P.; Tao, J.; Zhong, X. C.; Liu, X. J.; $\mathrm{Yi}, \mathrm{C}$. Q.; Xu, H. Identification of novel 7-amino-5-methyl-1,6naphthyridin-2 $(1 \mathrm{H})$-one derivatives as potent $\mathrm{PI} 3 \mathrm{~K} / \mathrm{mTOR}$ dual inhibitors. Bioorg. Med. Chem. Lett. 2014, 24, 790-793.

(19) Adams, N. D.; Burgess, J. L.; Darcy, M. G.; Donatelli, C. A.; Knight, S. D.; Newlander, K. A.; Ridgers, L. H.; Schmidt, S. J. Quinazoline derivatives as PI3 kinase inhibitors. WO2008157191, December 24, 2008.

(20) Morgentin, R.; Pasquet, G.; Boutron, P.; Jung, F.; Lamorlette, M.; Maudet, M.; Ple, P. Strategic studies in the syntheses of novel 6,7substituted quinolones and 7- or 6-substituted 1,6- and 1,7naphthyridones. Tetrahedron 2008, 64, 2772-2782.

(21) Li, Q.; Woods, K. W.; Zhu, G. D.; Fischer, J. P.; Gong, J. C.; Li, T. M.; Gandhi, V.; Thomas, S. A.; Packard, G.; Song, X. H.; Abrams, J. N.; Diebold, R. Dinges, J.; Hutchins, C.; Stoll, V.; Rosenberg, S. H.; Giranda, V. L. Kinase inhibitors. WO2003051366, June 26, 2003.

(22) Han, F. B.; Lin, S. W.; Liu, P.; Tao, J.; Yi, C. Q.; Xu, H. Synthesis and structure-activity relationships of PI3K/mTOR dual inhibitors from a series of 2-amino-4-methylpyrido[2,3-d]pyrimidine derivatives. Bioorg. Med. Chem. Lett. 2014, 24, 4538-4541. 